\title{
O CONSUMO DE ELETRÔNICOS EM UM GRUPO DE BAIXA RENDA: RELATOS DE UMA ETNOGRAFIA
}

\author{
THE ELECTRONIC CONSUMPTION IN A LOW- \\ INCOME GROUP: REPORTS OF AN ETHNOGRAPHY
}

Recebido 13/06/2012 Aceito 30/07/2012

Marcelo de Rezende Pinto ${ }^{1}$

\section{RESUMO}

Uma vez que os estudos sobre consumo ocupam hoje uma posição de relevância tanto no campo da pesquisa do consumidor como no das ciências sociais, atrelada à percepção de que pouco se pesquisou sobre o universo simbólico dos indivíduos de baixa renda, buscou-se, por meio desta pesquisa, investigar a seguinte questão: como as experiências de consumo de eletrônicos pelos consumidores de baixa renda interagem com o sistema cultural e simbólico envolvido no fluxo da vida social cotidiana. Para isso, conduziu-se uma pesquisa de inspiração etnográfica, a fim de conhecer melhor o dia a dia dos consumidores no seu ambiente natural por meio de entrevistas em profundidade, observações e notas de campo. Os dados da investigação empírica foram examinados com base na Análise de Conteúdo. Como resultado, pode-se salientar que, nas experiências de consumo de aparelhos eletrônicos de consumidores pobres, é possível perceber uma intensa relação com o sistema cultural e simbólico construído pelos sujeitos pesquisados.

Palavras-chave: Consumo, Eletrônicos, Baixa renda, Etnografia.

1 Possui graduação em Administração pela Universidade Federal de Juiz de Fora - UFJF, mestrado e doutorado em Administração pela Universidade Federal de Minas Gerais - UFMG. Atualmente é professor da Pontifícia Universidade Católica de Minas Gerais - PUC/MG. Belo Horizonte, Minas Gerais, Brasil. E-mail: marcrez@hotmail.com. 


\section{ABSTRACT}

Since the studies on consumption today occupy a position of importance in both the field of consumer research, as in the social sciences, linked to the perception that little has researched the symbolic universe of low-income individuals, we sought through this research to investigate the following question: how the experiences of consumer electronics for low-income consumers interact with the cultural and symbolic system involved in the flow of everyday social life. For this, we conducted an ethnographic study of inspiration in order to experience the daily life of consumers in their natural environment through in-depth interviews, observations and field notes. The empirical research data were examined based on content analysis. As a result, it can be noted that the experiences of consumer electronics to poor consumers can realize an intense relationship with the cultural and symbolic system built between individuals.

Keywords: Consume, Electronics, Low income, Ethnography.

\section{INTRODUÇÃO}

Os estudos sobre consumo ocupam hoje uma posição de relevância tanto no campo da pesquisa do consumidor como no das ciências sociais (CAMPBELL, 1991). Esse interesse pelo consumo veio acompanhado de uma considerável troca interdisciplinar e estabeleceu pontes entre pesquisadores dos mais diversos assuntos, como é o caso das relações entre marketing, comunicação e antropologia. Esse movimento relacionado ao aumento do interesse pelo consumo merece atenção e clama por explicação, já que consumir é uma das atividades mais básicas do ser humano, além de ser um dos fenômenos mais importantes das sociedades modernas (BARBOSA; CAMPBELL, 2006).

Na visão de Barbosa e Campbell (2006), o consumo é um processo social profundamente elusivo e ambíguo. É elusivo pois, ainda que seja um pré-requisito para a reprodução física e social de qualquer sociedade humana, somente se toma conhecimento de sua existência quando é classificado, nos moldes dos padrões ocidentais, como supérfluo ou ostentatório. Do contrário, sua presença em nosso dia a dia passa inteiramente despercebida ou é apreendida como falta ou carência de consumo. É considerado ambíguo porque, algumas vezes, é entendido como uso, manipulação e/ou experiência; outras vezes, como exaustão, esgotamento e realização. É importante frisar que, conforme Barbosa e Campbell (2006), essa ambiguidade inicia-se na própria etimologia do termo "consumo", derivado do latim consumere, que significa "usar tudo", "esgotar" e "destruir", e do termo inglês consummation, que significa "somar", "adicionar". Vale afirmar que, no Brasil, o significado do termo "consumo" ficou mais próximo da primeira dimensão, que tem sentido negativo.

Nesse sentido, Barbosa (2006) ressalta que no Brasil é negado a determinados grupos sociais o status de membros de uma sociedade moderna e de consumo, uma vez que é enfatizada nos estudos no campo das ciências sociais a dimensão de minoria discriminada e excluída destes. Isso é claramente perceptível nos estudos envolvendo os segmentos sociais $C$ e $D$, pesquisados quase que exclusivamente com foco em sua carência material e na desigualdade social. Contudo, cabe lembrar que o padrão de vida dos consumidores pobres não pode ser pensado apenas como uma função do nível de rendimentos. De um lado, a relação renda-consumo é sempre mediada pela família, no âmbito da qual se tomam as decisões sobre o que consumir e sobre como conseguir a renda necessária para a realização de um projeto grupal; a casa própria talvez seja o melhor exemplo disso. De outro lado, a decisão sobre o que consumir não é totalmente arbitrária, mas está pautada em uma série de padrões e costumes, além do fato de ter de atender a uma série de necessidades.

O estilo de vida e o gosto são elementos culturais e sociais, o que implica que, por mais que se deixe espaço livre para as opções individuais, elas são sempre feitas com referência a um conjunto de regras compartilhadas por um grande número de pessoas, formadoras de grupos so- 
ciais. Tanto em um sentido como em outro, ou seja, tanto tendo em vista a maneira como se tomam as decisões como quanto tendo em vista os valores que a orientam, pode-se afirmar que a experiência do consumo é um fenômeno social constituído por ações cotidianas (CALDEIRA, 1984).

Sendo assim, no entender de Barbosa (2006), tem sido ignorado pelos pesquisadores brasileiros um conjunto de temas de investigações que podem levar a uma melhor compreensão dos atos de consumo, de seus sujeitos e contextos, como: análises históricas baseadas em fontes primárias; pesquisas de campo e etnografias sobre práticas, padrões e rituais de consumo e compra de diferentes grupos sociais, faixas etárias, gêneros; religiões; mecanismos de mediação aos quais se encontra submetida à cultura material e seu papel no mundo contemporâneo e, por fim, estudo dos objetos e o que eles ensinam sobre a sociedade brasileira.

Uma questão, porém, ainda parece gerar certa curiosidade quando se busca estudar mais a fundo as investigações sobre o consumo. Percebe-se que, no Brasil, a despeito da inequívoca maioria numérica de alguns estratos da população, é negado a determinados grupos sociais o status de membros de uma sociedade moderna e de consumo, uma vez que é enfatizada nos estudos, a dimensão de "minoria discriminada e excluída" destes (BARBOSA, 2006). Isso é claramente perceptível nos estudos envolvendo os segmentos sociais $C$ e $D$, pesquisados quase que exclusivamente com foco de sua carência material e desigualdade social. Essa suposição, porém, não coincide com a suposição de que os indivíduos provenientes do mercado consumidor dito "popular", "pobre" ou de "baixa renda" consomem e que, mesmo que não tenham condições materiais de comprar todos os produtos e adquirir os serviços oferecidos, entram em contato com os símbolos e valores desse universo (BARROS, 2006).

É justamente nesse contexto de "abertura" para o entendimento do consumo por meio de novos olhares e perspectivas, juntamente com a percepção de que investigações precisam ser conduzidas para se entender o cotidiano de diversos grupos de consumidores até então negligenciados pelos pesquisadores do consumo (PINTO e LARA, 2008), que surgiu o interesse em empreender uma pesquisa empírica na qual se investigasse a forma como os consumidores brasileiros oriundos das classes mais populares vivenciam suas experiências de consumo. Dessa forma, colocou-se como objetivo geral do trabalho a seguinte questão: investigar como as experiências de consumo de eletrônicos pelos consumidores de baixa renda interagem com o sistema cultural e simbólico envolvido no fluxo da vida social cotidiana. Para atingir esse objetivo, adotou-se uma perspectiva interpretativa de investigação, a partir de uma abordagem etnográfica.

Para isso, inicialmente, foi elaborada uma seção visando revisar sucintamente alguns pontos importantes atinentes ao consumo em uma perspectiva antropológica. A seção posterior destaca o percurso metodológico adotado no estudo, e, em seguida, são apresentados os principais resultados do trabalho, com ênfase nos relatos das observações e dos discursos dos sujeitos envolvidos. Na sequência, uma seção intitulada (re)encontro com a literatura foi elaborada a fim de confrontar os resultados da pesquisa com a literatura pesquisada. Na última seção, algumas reflexões gerais são apresentadas.

\section{O CONSUMO EM UMA PERSPECTIVA ANTROPOLÓGICA}

Uma das primeiras teorias do consumo em uma perspectiva antropológica surgiu no início do século XX, no livro "A Teoria da Classe Ociosa", de Thorstein Veblen, em que este sustenta a tese de que há uma modalidade de consumo que é ostentatório, isto é, aquele que é realizado com a finalidade de demonstrar a condição social. O autor chama esse consumo de "conspícuo", o qual é manifestado socialmente pela classe ociosa, isto é, a diferenciação significativa entre as 
ocupações da classe ociosa e as demais implicava a hierarquia da sociedade. $\mathrm{O}$ aparecimento de uma classe ociosa coincidiu com o início da propriedade privada, uma vez que as duas instituições resultam do mesmo conjunto de forças econômicas (VEBLEN, 1988).

A "novidade" apresentada por Veblen em sua obra reside no fato de ele ampliar o foco do modo de compreender o objetivo da aquisição e da acumulação de bens para além do objetivo economicamente legítimo da aquisição, que caberia à teoria econômica explicar. $O$ autor compreende o consumo como um atendimento tanto das necessidades físicas do consumidor como de suas necessidades mais elevadas, espirituais, estéticas, intelectuais ou outras. Em outras palavras, esta última classe de necessidades seria atendida indiretamente pelo consumo de bens, segundo a maneira pela qual é familiar aos adeptos de teorias econômicas.

Marshall Sahlins, no livro "Cultura e Razão Prática”, corrobora as proposições de Veblen ao defender uma crítica antropológica da ideia de que as culturas humanas são formuladas a partir da atividade prática e do interesse utilitário. Para ele, o significado é a propriedade específica do objeto antropológico. As culturas são ordens de significado de pessoas e coisas.

Sahlins (2003) afirma que o funcionalismo utilitário é uma cegueira funcional, visto que o conteúdo é apreciado somente por seu efeito instrumental, sendo sua consistência interna, por consequência, modificada por sua utilidade externa. Porém, nenhuma explicação funcional por si só é suficiente, já que o valor funcional é sempre relativo a um esquema cultural. Dessa forma, as finalidades, assim como as modalidades de produção, são provenientes do âmbito da cultura, ou seja, dos meios materiais da organização cultural. Por sua vez, as forças materiais por si só não têm vida. Seus movimentos específicos e suas consequências determinadas somente podem ser estipuladas agregando-se estas às coordenadas da vida cultural.

A obra da antropóloga Mary Douglas e do economista Baron Isherwood, publicada pela primeira vez em 1978, com o título de "The world of goods: towards an anthropology of consumption", é considerada um clássico da antropologia do consumo. Os autores defendem a ideia de que o consumo é algo ativo e constante em nossa vida diária e de que é nela que o consumo desempenha um papel central como estruturador de valores que constroem identidades, regulam relações sociais, definem mapas culturais, etc. Nesse sentido, os bens são revestidos de valores criados socialmente tanto para expressar categorias e princípios quanto para cultivar ideias, fixar e sustentar estilos de vida ou enfrentar mudanças.

Douglas e Isherwood (2006) criticam a perspectiva racional dos modelos de pesquisa do consumidor, pois, para eles, a noção do indivíduo racional é uma abstração impossível da vida social. Na visão dos autores, seria absurdo agregar milhões de indivíduos que compram e usam diversos produtos e serviços sem considerar as transformações que provocam em seu cotidiano ao compartilharem o consumo. Ademais, "os bens não são neutros, seus usos são sociais; podem ser usados como cercas ou pontes" (DOUGLAS; ISHERWOOD, 2006, p. 36).

Em síntese, os bens, na perspectiva de Douglas e Isherwood (2006), são acessórios tanto para os rituais quanto para a marcação. Funcionam como acessórios dos rituais pois o consumo pode ser tratado como um processo ritual cuja função primária é dar sentido ao fluxo incompleto dos acontecimentos, ou seja, servem para conter a flutuação dos significados. São acessórios para a marcação, pois podem servir para marcar os intervalos entre meses, anos, acontecimentos importantes, fases da vida, entre outros. Portanto, os bens são a parte visível da cultura, por estarem organizados em perspectivas e hierarquias que podem dar espaço para a variedade total de discriminações de que a mente humana é capaz. Os bens, nesse sentido, são portadores de significado, que está nas relação entre todos os bens, assim como a música está nas relações marcadas pelos sons, e não em qualquer nota. 
Outro autor importante, nesse contexto, é o sociólogo francês Pierre Bourdieu. Alguns argumentos importantes desenvolvidos por ele têm aderência à questão do consumo, em uma perspectiva antropológica. Bourdieu afirma que o consumo é cultural visto que, ao consumirem, as pessoas tanto exercem seus gostos ou estilos - os quais não são uma questão de capricho pessoal; são estruturados socialmente - quanto os exibem. Ao expressarem ou exibirem seus gostos, com efeito, os consumidores estão expondo aos outros indícios de sua posição social (BOURDIEU, 1989; 2007a; 2007b).

Um conceito central de Bourdieu é o de habitus, que pode ser considerado como uma estrutura de "disposições", isto é, como um sistema de classificação, pautado por regras e expectativas, que predispõe o indivíduo a fazer certas escolhas e realizar certas ações. O papel do habitus é levar à interiorização de crenças, verdades, comportamentos e atitudes. Ao estender o conceito de habitus ao modo de vida do consumidor, é possível estabelecer que todo objeto escolhido, assim como todo ritual de consumo, está ou pode estar voltado a cálculos precisos de movimentos e restrições possíveis. Por exemplo, Bourdieu (2007b) insinua que a cultura e o consumo da classe operária são determinadas pela "escolha do necessário". Ao afirmar que "nada é mais estranho às mulheres das classes populares que a ideia, tipicamente burguesa, de transformar cada objeto de seu interior na ocasião de uma escolha estética" (p. 355), o autor parece querer dizer que elas não podem se dar ao luxo da estética por causa da pobreza econômica, mas que o "necessário" é escolhido a partir de um habitus, fruto de uma estrutura de cognições, ao mesmo tempo em que é formada por experiências coletivas e de longa data e transmitidas das limitações econômicas de sua posição de classe.

Daniel Miller, outro antropólogo e estudioso do consumo, também pode ser citado como uma referência importante. Miller (2002) resgata um tema abandonado pelos antropólogos no século XIX, a "cultura material", explicitando que esta não é uma consequência direta dos mecanismos da economia capitalista. Tanto o capitalismo quanto o marketing desempenham um papel importante na criação do desejo, mas não são os únicos determinantes de onde, quando e como as relações sociais estarão sujeitas a um processo de comoditização.

Relacionando cultura e consumo, McCracken (2003) é outro pesquisador defensor da ideia de que o consumo é moldado, dirigido e constrangido em todos os aspectos por considerações culturais. A contribuição desse autor para o entendimento do consumo em uma perspectiva antropológica direciona-se para pelo menos quatro questões importantes. A primeira questão está relacionada à tentativa de construção da história do consumo a partir do século XVI na Europa. Com base em estudos de historiadores e pesquisadores do consumo, McCracken (2003) parece aceitar a tese de que foi ignorada pela história tradicional a Revolução do Consumo, que seria companheira necessária e essencial para a Revolução Industrial, uma vez que uma mudança nos meios e nos fins produtivos não poderia ter ocorrido sem uma mudança nos gostos e nas preferências dos consumidores. A segunda questão mantém relação com o conceito de pátina, que consiste em pequenos signos de idade que se acumulam na superfície de objetos como mobília, pratarias, cutelarias, construções, joias, roupas e outros objetos de manufatura humana. A pátina funcionaria como uma espécie de prova visual do status do seu proprietário. A terceira questão seria a discussão que McCracken (2003) chama de "significado deslocado", a qual consiste na "remoção" de um significado cultural da vida cotidiana de uma comunidade e sua realocação em um domínio cultural distante. Faz-se importante ressaltar o fato de que os bens são pontes para o significado deslocado e, desta feita, os objetos contam não quem são os consumidores, mas quem nós gostaríamos de ser. Por fim, a quarta contribuição de McCracken (2003) para o campo do entendimento do consumo em uma perspectiva antropológica está re- 
lacionada a que ele chama de "efeito Diderot", que sugere que os bens de consumo, de alguma maneira complementares, são ligados por certa comunalidade ou unidade. Isto significa dizer que as coisas têm uma espécie de harmonia ou consistência e, portanto, "andam juntas".

Outro autor que contribui para as discussões da antropologia do consumo é Colin Campbell. Em primeiro lugar, Campbell (2001) advoga em defesa de que, anteriormente à Revolução Industrial, houve uma Revolução do Consumo, a qual é negligenciada pelos pesquisadores. $\mathrm{O}$ autor compreende que a Revolução Industrial constituiu em uma dramática transformação, pois houve um concomitante desenvolvimento e uma ampliação do consumo. Contudo, essa nova propensão ao consumo teve origem em uma mudança de valores e atitudes, a qual não se confinou ao significado econômico do comportamento do consumidor. Essas mudanças, que constituiriam uma revolução do consumo, foram provenientes da expansão das atividades das horas vagas, inclusive a leitura de romances, juntamente com a ascensão da moda e do amor romântico.

A partir da discussão desses autores quanto à visão antropológica do consumo, percebe-se uma carência de teorias que levem em consideração a questão simbólica do consumo de consumidores no contexto cultural brasileiro. Todas as obras e os autores citados desenvolveram suas teorias em outros contextos históricos e culturais. Ademais, os consumidores de baixa renda, não raramente, são sequer mencionados nos estudos acadêmicos. É, portanto, nessa lacuna do conhecimento que se insere a proposta da pesquisa, cujos procedimentos metodológicos adotados serão discutidas na próxima seção.

\section{MÉTODO}

A escolha do método de "inspiração etnográfica" justifica-se nesse pesquisa devido à necessidade de se acompanhar o dia a dia do grupo estudado em seu contexto "natural". Também é importante salientar que o trabalho descritivo dos estudos com base na disciplina antropológica, com sua capacidade de levantar perspectivas diferentes e interpretações alternativas, apresenta um material tanto provocativo quanto estimulante para repensar a realidade social (DURHAM, 1996; FLACH, 2011). Não menos importante é a constatação de que a proposta do trabalho é lançar mão de um modo privilegiado de análise cultural e, com efeito, é importante para o entendimento dos sistemas simbólicos que articulam os objetos de consumo e o cotidiano dos atores sociais (ROCHA e ROCHA, 2007), ao mesmo tempo em que ressalta a importância dos significados subjetivos na construção e reconstrução da realidade dos indivíduos pesquisados (SACCOL, 2009).

O locus no qual a pesquisa foi desenvolvida está situado em uma das áreas mais pobres do município de Belo Horizonte, denominada Aglomerado da Serra, composta por diversas vilas, dentre elas: Nossa Senhora de Fátima, Nossa Senhora da Aparecida, Nossa Senhora da Conceição, Santana do Cafezal, Vitório Marçola e Cafezal. Essas vilas estão localizadas em terrenos de acentuada declividade e são cortado por nascentes e córregos, que se localizam em encostas íngremes. Algumas áreas apresentam risco geológico em grau alto e muito alto (PREFEITURA DE BELO HORIZONTE, 2008).

Dadas as características da pesquisa, cumpre ressaltar a importância do trabalho de campo, pois ele é o elemento mais característico da pesquisa etnográfica. $O$ trabalho de campo pressupõe uma interiorização, por parte do pesquisador, das significações que os indivíduos atribuem aos seus comportamentos, implicando uma integração do observador no trabalho de campo. Dois aspectos são importantes para o emprego da etnografia. O primeiro refere-se ao recurso da tomada de notas e da elaboração sistemática do diário de campo. O segundo aspecto refere-se à complementaridade de outros procedimentos para a coleta de dados durante o trabalho de campo: análise 
de documentos, entrevistas semiestruturadas e história de vida (ANDION; SERVA, 2006).

O trabalho de campo iniciou-se ainda no período de elaboração do projeto da tese, quando o pesquisador passou a conversar informalmente com os moradores, a fim de identificar alguns traços básicos do cotidiano deles e compreender a dinâmica das relações entre eles. Essa fase do trabalho, de forma não sistemática e eminentemente exploratória, aconteceu durante os meses de janeiro a maio de 2008 e não contou com o apoio de nenhum instrumento de pesquisa além da anotação de algumas notas sobre aspectos que o pesquisador considerava relevante.

A segunda fase do trabalho de campo, que se estendeu dos meses de maio de 2008 a fevereiro de 2009, foi marcada por conversas informais, visitas às casas dos moradores e, principalmente, pela realização de entrevistas semiestruturadas. Nas visitas às casas dos moradores, o pesquisador buscou sempre perceber detalhes no tocante ao acabamento, à organização e à decoração dos móveis, ao lugar de instalação dos aparelhos ou a qualquer outro aspecto que pudesse contribuir para o entendimento do dia a dia desses indivíduos.

Finalmente, a terceira fase do trabalho de campo teve por objetivo fazer checagens com algumas das entrevistadas acerca de algumas categorias que emergiram da análise executada e tentar aumentar a densidade da teoria em construção. Essa fase aconteceu durante o mês de março de 2009 e marcou o fim do trabalho de campo, pois o pesquisador julgou que havia atingido o que Strauss e Corbin (2008, p. 143) chamam de "saturação teórica", que pode ser descrita como "o ponto no desenvolvimento da teoria em que não surgem novas propriedades, dimensões ou relações durante a análise".

No tocante à escolha das entrevistadas, no caso deste trabalho, a mais adequada foi a denominada "amostragem teórica" (STRAUSS; CORBIN, 2008), pois, quando se constrói uma teoria, indutivamente a amostragem é direcionada pela própria teoria. Assim, pode-se definir amostragem teórica como coleta de dados conduzida por conceitos derivados da teoria evolutiva e baseada em "fazer comparações", cujo objetivo é procurar locais, pessoas ou fatos que maximizem oportunidades de descobrir variações entre conceitos e de tornar densas as categorias em termos de suas propriedades e de suas dimensões (STRAUSS; CORBIN, 2008, p. 196). Assim, 13 moradoras fizeram parte do corpus da pesquisa. A idade delas variava de 20 a 66 anos. A maior parte delas havia concluído apenas o ensino fundamental e trabalhava em atividades de baixa remuneração. Além disso, a fim de obter uma visão um pouco diferenciada dos discursos dos moradores, optou-se por incluir no rol de entrevistados alguns profissionais que atuavam no bairro.

Como técnica de análise de dados, optou-se pela utilização da análise qualitativa de conteúdo (BARDIN, 1977), uma vez que o objetivo era identificar o que estava sendo dito a respeito das experiências dos consumidores de baixa renda. Assim, o pesquisador pôde ater-se mais às nuanças de sentido e aos elos lógicos que existem entre essas unidades ou entre as categorias que as reúnem.

\section{O BAIRRO E SEU COTIDIANO}

O bairro apresenta algumas características típicas de um bairro residencial ou, até mesmo, de uma cidade do interior, onde as crianças podem frequentar a rua longe do olhar cuidadoso dos pais e responsáveis. No interior do bairro, era comum encontrar crianças andando de bicicletas, soltando pipas ou sentadas na calçada, conversando ou brincando com objetos simples. O comércio existente era bastante simples, com sede quase sempre construída junto à casa de seus proprietários, funcionando como uma continuação de sua residência. $O$ atendimento, normalmente, era realizado pelo dono ou por algum de seus familiares, como mulher e filhos. Costumeiramente eram vendidos produtos básicos, com pouco estoque disponível. A fachada e 
o interior do estabelecimento, no que tange ao acabamento não é muito diferente do que era possível verificar nas casas. Isto é, não existia uma preocupação com o acabamento.

Era bastante comum encontrar pequenos botequins que, principalmente nos finais de semana, ficavam bastante movimentados, com homens bebendo cerveja e comendo algum tiragosto. Esses estabelecimentos também vendiam produtos de primeira necessidade e invadiam o espaço dos becos. Ademais, era fácil encontrar diversos animais domésticos, principalmente cães, perambulando pelos becos. Ouviam-se por todos os lados sempre músicas em alto volume. Às vezes, umas confundiam-se com as outras.

Faz-se relevante destacar a relação de amizade e "proximidade" percebida pelo pesquisador, na época, entre os moradores do bairro. Foi possível registrar situações em que as pessoas que o pesquisador acompanhava sempre se mostravam simpáticas e corteses com todos os vizinhos e moradores que encontravam no caminho, cumprimentando-os com sorriso nos lábios. As características geográficas do bairro facilitavam esse contato. Em primeiro lugar, devido ao grande número de becos estreitos, o contato visual era bem mais facilitado. Em segundo lugar, a proximidade das casas e o fato de as casas serem muito próximas do local de trânsito das pessoas também propiciavam maior facilidade de contato. Outra aspecto que corroborava para isso era a alta declividade dos terrenos nos quais se assenta grande parte do bairro, o que forçava a pessoas a caminharem mais lentamente.

Quanto aos hábitos de compra, por diversas vezes o pesquisador colheu depoimentos de pessoas que disseram não ter hábitos de fazer compras para casa poucas vezes por mês nem em grande quantidade. Como muitos dos moradores recebem "cestas básicas", seja das empresas em que trabalham ou de entidades beneficentes atuantes no bairro, eles, não raramente, preferem fazer as compras de mantimentos e produtos de uso cotidiano em pequenas mercearias do próprio bairro ou nos arredores. Por isso, havia sempre um grande fluxo de pessoas nos pequenos mercados.

\section{A CASA E A FAMÍLIA DOS MORADORES}

Ainda que não se possa generalizar, foi possível determinar que a maioria das casas da vila pesquisada segue um mesmo padrão de construção, tamanho e acabamento. De acordo com as pessoas com que o pesquisador conversou e tendo em vista as casas visitadas, pode-se afirmar que grande parte das moradias era composta por poucos cômodos (quatro ou cinco, no máximo), os quais dividiam-se, normalmente, em sala, um ou dois quartos, cozinha e banheiro, independente do número de moradores. Era bastante comum a construção de casas umas junto às outras, em locais que os moradores chamam de "área", o terreno possuído pela família. Esse fato dificulta uma delimitação perfeita entre as moradias, pois o consumo de luz e água é único. Quanto ao acabamento, a maioria das moradias não apresentava reboco, chão de cimento e cobertura de laje, embora fosse comum também a cobertura de telhas. Assim, foi difícil encontrar casas com "luxos" como pinturas, azulejos e pisos. A maioria das casas, principalmente as da parte mais "nobre" da favela, possuía rede de água e esgoto.

Desde o início da convivência do pesquisador com os moradores do bairro, este começou a observar que uma das características marcantes de várias casas era o fato de elas estarem constantemente em obras. Depois, o pesquisador veio a saber que isso acontecia em virtude da disponibilidade do orçamento para a realização da construção de um novo quarto, de uma sala maior ou de um banheiro mais bem "acabado". O pesquisador notou que se valorizam pouco os "detalhes" relacionados ao acabamento dos banheiros e das cozinhas; era usual verificar canos 
da rede de água e fiação de chuveiros, por exemplo, à vista.

Ademais, o pesquisador percebeu que, em geral, devido ao modo improvisado e sem planejamento como as moradias eram construídas, os cômodos eram escuros e sem ventilação. Vale ressaltar, porém, que, em algumas regiões mais altas da favela, o nível de qualidade da construção das casas diminuía consideravelmente, sendo possível encontrar "barracões" construídos com restos de madeiras e lata, sem acesso à rede de água e esgoto.

Dessa forma, a percepção do pouco espaço, aliada à constatação de um certo "entulhamento" dos móveis e do aspecto inacabado das construções, levou o observador, em um primeiro momento, a constatar uma sensação de "bagunça" ou "desordem". Porém, essa sensação foi aos poucos sendo transformada, pois pode-se observar também que existia uma preocupação explícita por parte das moradoras com o cuidado com a moradia, no sentido de torná-la mais agradável. Além do mais, é bastante comum o uso de enfeites, quase sempre, bastante coloridos, ainda que simples, como quadros nas paredes, cortinas, toalhas nas mesas e outros objetos decorativos em geral. Nesse caso, o enfeite tem um valor simbólico interessante. 0 pesquisador verificou essa questão ao conversar com algumas donas de casa, principalmente as mais velhas, as quais afirmavam que, embora suas casas fossem simples e mal acabadas, tinham orgulho em mantê-la sempre limpa e enfeitada. Sendo assim, o enfeite desempenha o papel de explicitar o cuidado e o asseio da moradora para com sua casa. De interesse para esta pesquisa foi também a constatação de que na maioria das casas, apesar do aspecto simples e inacabado, era comum encontrar todos os tipos de aparelhos eletrônicos e eletrodomésticos existentes, não raramente, os de última geração.

O importante a ressaltar é que muitas casas, principalmente aquelas cujos proprietários eram moradores antigos do bairro, representavam algo que chamou bastante a atenção do pesquisador em várias conversas. A casa, para os moradores, é a "consolidação" de muitos anos de trabalho e sacrifício, e incida/significa "conquista", "orgulho", "dedicação", "recompensa". Alguns deles chegaram a se emocionar ao comentarem as dificuldades e carências a que a família foi submetida ao longo de anos a fim de conseguir construir sua casa própria e mobiliá-la adequadamente. Outros também se recordaram, com certa dose de nostalgia, dos inúmeros problemas que enfrentaram quando o bairro ainda era "tudo matagal" e não havia rede de esgoto, água encanada, energia elétrica nem transporte próximo.

Na loja de móveis instalada no Aglomerado da Serra, o pesquisador ouviu algumas histórias contadas pelos vendedores e entregadores que ilustraram a questão do pequeno espaço das casas. Em uma das situações narradas, um guarda-roupas precisou ser devolvido porque não conseguiram fazê-lo entrar pela porta nem pela janela da casa do comprador, mesmo após tê-lo desmontado parcialmente. Em outra situação relatada ao pesquisador, um dos entregadores caiu em um cômodo da casa ao lado ao tentar apoiar-se na parede, que era feita de um tipo de madeira de qualidade bastante ruim. Também não é incomum para os moradores precisar pedir a permissão para invadir o quintal ou a "laje" do vizinho para fazer passar algum móvel de maior tamanho.

No tocante às famílias dos moradores, foi possível chegar a algumas constatações que parecem interessantes para esta pesquisa. Primeiramente, verificou-se a existência de novos "arranjos" familiares que fogem ao tradicional "marido-mulher-filhos". Isso foi constatado logo nos primeiros contatos com os moradores do Cafezal. Muitas das entrevistadas mais velhas tiveram oito filhos. Porém, isso não foi característica marcante das mulheres mais velhas. Das entrevistadas que estavam na faixa dos trinta anos, uma delas possuía oito e outra cinco filhos, número muito acima da média nacional. 


\section{O PAPEL DOS RELACIONAMENTOS}

Esta categoria emergiu dos dados após o pesquisador ter verificado que os relacionamentos eram extremamente importantes no cotidiano dos moradores do Cafezal. Este relacionamento pode ser atribuído à proximidade entre os moradores, já que as casas são construídas muito próximas umas das outras. O fato de em um mesmo terreno, ou "área", como os moradores chamam, instalarem-se várias famílias pode ter contribuído para o aumento da importância dos relacionamentos dos pobres urbanos. Não raramente, muitos namoros e casamentos ocorrem entre integrantes das famílias vizinhas. Dessa forma, é comum que os filhos, após o casamento, passem a residir nas proximidades, o que reforça os laços familiares. Nesse contexto, as relações de vizinhança envolviam conflitos e alianças. Em muitos casos, ocorriam situações desagradáveis por motivos de fofocas e outros problemas relacionados à convivência muito próxima entre as pessoas. Ainda que a maior parte das redes sociais construídas estivesse embasada nas relações de parentesco, os "parentes", quase sempre, são selecionados em um contexto mais amplo de relacionamentos sociais.

Foi possível verificar, por diversas vezes, situações de ajuda mútua entre as moradoras de casas próximas, nas quais as mulheres, sem muita "cerimônia", dirigiam-se à casa da vizinha para pedir emprestada alguma panela, algum utensílio a ser utilizado para afazeres domésticos ou, até mesmo, um pouco de arroz, farinha, açúcar ou tempero que havia faltado para terminar o preparo de alguma refeição. $O$ empréstimo de roupas entre parentes, principalmente mulheres, também era bastante comum.

Este relacionamento "estreito" parece ter tido certa influência nas formas de consumo dos pobres urbanos pesquisados. Uma questão que emergiu desde a primeira entrevista foi o "empréstimo" do nome de alguém que tenha acesso ao crédito (que pode ser o patrão, um familiar, um vizinho) para comprar algo. No "vocabulário" dos pobres urbanos essa situação é chamada de "tirar", e pode ser compreendida como uma forma de aquisição de produtos por parte dos consumidores de baixa renda que não têm acesso aos sistemas de crédito. $O$ interessante é que este hábito apresentou-se como comum em todas as faixas de idades e era conhecido por todos.

Apesar de comum e altamente utilizado, o procedimento de "tirar" era considerado como arriscado por algumas das entrevistadas, pois envolvia a possibilidade de ter o "nome sujo", o que é bastante mal visto pela sociedade, motivo pelo qual muitas delas tomavam cuidados para evitar problemas, embora buscassem negar o "favor" com uma certa dose de cautela.

Ainda quanto à questão dos relacionamentos, o pesquisador percebeu que a vizinhança tinha uma influência marcante na vida dos moradores da favela. Muitas entrevistadas não economizavam elogios ao se referirem aos vizinhos, chegando a tratá-los como parentes. Também era comum tratar a casa dos vizinhos como "continuação" das suas moradias, por se notar o compartilhamento de alguns espaços "em comum" entre as casas.

Muitas vezes, a força dos relacionamentos entre os moradores transformava-se em ajuda. A intermitência dos empregos, atrelada à inconstância na renda e ao desemprego, que sempre fez parte da vida cotidiana dos moradores da favela, intensificava a relação de dependência da rede de parentesco e de amizade. Era bastante comum a organização de mutirões para auxiliar na construção ou melhoria da casa de algum morador, contando com a participação de familiares, vizinhos e amigos. 


\section{COMPARTILHAMENTO DE OBJETOS E ESPAÇOS}

Relacionada à questão da importância dos relacionamentos entre os pobres urbanos, outra questão emergiu do convívio do pesquisador com o grupo pesquisado: o compartilhamento de objetos e espaços. Em várias ocasiões, percebeu-se muito claramente a existência do hábito de troca e do empréstimo de aparelhos, roupas e objetos tanto entre integrantes de uma família quanto entre pessoas conhecidas e vizinhos. Conforme exposto na seção anterior, entre as donas de casa era fácil observar o compartilhamento e a troca de mantimentos e pequenos objetos domésticos.

Além do compartilhamento, é bastante comum a venda de produtos entre os integrantes de diferentes famílias, muito em decorrência, conforme já comentado anteriormente, da proximidade entre os moradores, pois muitos precisam passar pela casa do vizinho para ter acesso à sua residência. Outras vezes, da janela de uma das casas o morador vê o que está acontecendo na casa do outro. Além disso, ainda existe um compartilhamento das áreas comuns entre as casas, como as lajes, os becos e os quintais. A laje da casa é valorizada pelos moradores, pois representa um espaço importante da casa que leva a uma forma de distinção da moradia, uma vez que pode ser utilizada para receber amigos e parentes, bem como pode servir de local de convivência da família.

No tocante ao uso dos aparelhos eletrônicos, foi possível observar sua existência. Como as famílias são numerosas e as casas são pequenas, o compartilhamento de todos os aparelhos é quase regra. Nas conversas informais, as pessoas sempre afirmavam que a televisão, o DVD e o aparelho de som eram instalados na sala para favorecer a utilização por parte de todos os familiares. É importante enfatizar que a preocupação das mães em mostrar para seus filhos, desde criança, a importância de compartilhar os objetos da casa também foi percebida pelo pesquisador.

\section{DISTINÇÃO}

Desde o início do convívio do pesquisador com os moradores da favela, este começou a perceber que, ao mesmo tempo em que havia certa tendência de homogeneidade entre as pessoas quanto aos seus hábitos, seus costumes, suas maneiras de pensar e suas formas de aquisição de produtos, era possível sentir que também existiam algumas diferenças entre eles que precisavam ser mais bem investigadas. Apesar de serem sutis e aparentemente irrelevantes, à medida que o estudo avançava, foi possível perceber que estas diferenças eram corporificadas em "detalhes", tais como localização da casa no bairro, o tempo de residência no bairro e, até mesmo, a posse de bens domésticos.

Em primeiro lugar, notou-se certa distinção quando os moradores mostravam diferenciarse ao afirmarem residir na parte "mais nobre" da favela, ou seja, na parte mais antiga e mais desenvolvida, na região mais plana e mais baixa, a qual tinha acesso aos principais serviços urbanos, como água encanada, esgoto, ruas asfaltadas, linhas de ônibus e escolas. Essa constatação ficou implícita em muitas conversas informais com os moradores, que se referiam à parte pior da favela como "a parte lá de cima", o local onde se encontravam as piores casas, esgoto a céu aberto e maiores índices de violência. Na "melhor região" havia lojas e mercados maiores. Também foi observada uma distinção entre aqueles que eram pobres e outros que eles consideravam mais pobres.

Alguns moradores sentiam-se orgulhosos de serem os primeiros moradores e terem vivenciado todo o crescimento e desenvolvimento do bairro. $O$ pesquisador ouviu alguns relatos de moradores que gostavam de contar, em tom nitidamente saudosista, as mudanças tanto positivas quanto negativas ocorridas na região nos últimos trinta anos. Nesse sentido, o fato de residir 
há muitos anos também confere distinção ao morador em relação aos outros.

Outra grande fonte de distinção advém da posse da casa própria. Isto é, o fato de o morador possuir "um teto" era condição valorizada tanto pelas pessoas entrevistadas quanto por outros moradores com os quais o pesquisador conversou informalmente durante a pesquisa. Embora a posse da casa fosse algo essencial, também se percebeu que outro aspecto distintivo mantinha relação com o acabamento da residência, em especial o reboco e a pintura. Apesar de considerados como elementos supérfluos, alguns poucos moradores que tinham suas casas rebocadas e pintadas gostavam de ressaltar que suas residências eram "diferentes" e destacavamse das demais. Somado à questão do acabamento das casas, vale destacar também o papel dos enfeites como algo diferenciador, pois muitas moradoras faziam questão de pontuar que gostavam de manter enfeites na sala e na cozinha, o que pode ser compreendido como uma forma de dizer que, embora sua casa fosse simples, havia preocupação com a limpeza e com o bem-estar da família e das visitas, inclusive com a tentativa de criação de um ambiente bonito e agradável principalmente estas últimas.

Outra importante fonte importante de distinção está relacionada à posse de aparelhos eletrônicos. Em quase todas as casas visitadas para a elaboração desta pesquisa, foi possível encontrar diversos aparelhos eletrodomésticos, como fogão, geladeira, forno e micro-ondas. A maioria das casas tinha televisão, DVD e aparelho de som, o que permite constatar que estes aparelhos não servem mais para conferir distinção para uma casa na região da pesquisa. Nesse caso, a distinção pode ser referente ao modelo e ao tamanho da televisão, bem como ao acesso a canais de TV a cabo, que começava a ser introduzido na favela no período da pesquisa de campo. De fato, no final do período de coleta de dados, o pesquisador passou a observar em vários pontos da favela faixas anunciando, a preços especiais e convidativos, a contratação de serviços de TV a cabo. Contudo, muitos moradores ainda insistiam na utilização do que era chamado por eles de "gatonet" ou "TV a gato", que consiste no acesso às redes de comunicação das empresas sem autorização e pagamento.

Ademais, com o lançamento da tecnologia de aparelhos mais avançados, mais potentes e com design inovador, muitos moradores buscaram diferenciar-se de seus pares com a obtenção destes produtos. As televisões de plasma ou de LCD, por exemplo, mesmo os modelos menores, ainda eram considerados objetos de luxo por parte dos moradores do Cafezal. No mesmo sentido, percebeu-se que o computador ( $\mathrm{e}$, em especial, o uso da internet) começava a fazer parte do cotidiano, principalmente, dos consumidores mais jovens da favela. Estes pontos podem ser citados como possíveis focos de distinção entre os moradores.

Também cabe mencionar a questão da localização dos aparelhos nas casas. Quase sempre os mais novos e mais modernos eram instalados na sala, de modo a permitir melhor visibilidade aos vizinhos ou às visitas. Duas explicações podem ser dadas para essa questão, uma relacionada com a preocupação com o compartilhamento dos aparelhos; outra com a distinção; isto é, os consumidores poderiam utilizar a posse dos bens para criar um diferencial entre a vizinhança. Nesse sentido, não bastaria somente ter o aparelho; seria preciso mostrar que o tem.

O pesquisador também pôde constatar que a posse de aparelhos eletrônicos denota uma suposta preocupação da dona de casa com o bem-estar de seus filhos, como se esta posse fosse uma forma de "minimização" dos aspectos negativos decorrentes de se morar em uma favela com poucas oportunidades de lazer e entretenimento. 


\section{FORMAS DE AQUISIÇÃO DOS APARELHOS}

Com a introdução do uso do cartão de crédito nas camadas mais populares, os pobres urbanos passaram a ter acesso ao crédito, e, com isso, houve aumento na compra de aparelhos novos. Contudo, mesmo com a emergência dos cartões de crédito e de débito, o hábito de "tirar" manteve-se e estendeu-se ao empréstimo do cartão, principalmente de crédito. Foi possível verificar algumas outras formas de aquisição que foram sendo apresentadas ao pesquisador através dos relatos dos pesquisados. Dentre estas formas, destacaram-se: compra em bazares existentes no próprio bairro, compra de aparelhos usados de vizinhos, parentes e amigos e compra de aparelhos de procedência "duvidosa".

Notou-se que uma modalidade de obtenção de produtos "não tradicional" por parte dos moradores do Cafezal é por meio de bazares, sejam estes beneficentes ou não. Cabe pontuar que vários objetos eram comprados neste tipo de comércio. A ocorrência é bastante comum em áreas pobres e constitui-se uma oportunidade para os consumidores terem acesso a produtos de melhor qualidade e com preços mais baixos.

É relevante pra esta pesquisa ressaltar que os consumidores da favela com quem o pesquisador conversou mostraram certa resistência em consertar os aparelhos eletrônicos. Muitos disseram não compensar, pois o valor cobrado pelo conserto ficava próximo do valor de um aparelho novo. Foi possível confirmar esta informação ao conversar com o dono de uma loja especializada em conserto de aparelhos eletrônicos que, na época da pesquisa, está localizada na Rua do Ouro, no bairro Serra, mas já teve oficinas de conserto em vários pontos do Aglomerado da Serra. Com experiência de 20 anos de atuação na área e morador do bairro, o dono da loja relatou que o movimento no estabelecimento veio caindo gradualmente nos últimos anos, pois a maioria dos consumidores não gosta de consertar aparelhos, preferindo, muitas vezes, adquirir um novo ou usado que esteja em bom funcionamento.

No entanto, todos os moradores da favela mostraram conhecer uma forma de aquisição de aparelhos que parecia fazer parte de suas rotinas: o comércio de aparelhos roubados ou obtidos de forma irregular ou ilegal. Ainda que muitos moradores tenham evitado se estender na discussão quando perguntados sobre a questão, foram relatado ao pesquisador depoimentos que provam que esta é uma forma importante de acesso dos moradores a aparelhos mais novos e atualizados tecnologicamente.

\section{DILEMA: PAGAMENTO À VISTA OU A PRAZO?}

Esta categoria foi incluída na discussão e faz parte da teoria substantiva em decorrência do dilema entre pagar as compras à vista ou a prazo, muito comum entre os consumidores de baixa renda pesquisados. Por meio das entrevistas e nas conversas informais que o pesquisador manteve com os moradores sobre o tema, foi possível constatar que este dilema é marcante nas decisões do consumidor e está bastante presente nos seus discursos, independentemente da idade. Neste caso, o grande dilema é juntar o dinheiro e comprar o produto à vista ou obter o bem de modo imediato, com dívidas para pagar, muitas vezes, com juros altos. Ainda que eles percebam que a melhor opção, economicamente, seria poupar parte de seus rendimentos e comprar o produto à vista, é aceito que, em decorrência dos parcos recursos que recebem, é difícil, na prática, conseguir guardar uma quantia dinheiro por vários meses.

Em algumas situações, a posse de bens foi colocada pelos pesquisados como algo "urgente", o que justificaria a compra a prazo para dar acesso rápido ao bem de consumo, fato acei- 
tável perante nossa sociedade atual, marcada pela velocidade. A grande questão, porém, é que, na visão destes consumidores, conforme se pôde constatar na pesquisa, todos os aparelhos são importantes e é relativamente inconcebível uma casa não ter aparelhos como geladeira, fogão, televisão, aparelho de som e outros. Alguns consumidores, por exemplo, ao serem perguntados sobre o que aconteceria se ficassem sem os aparelhos eletrônicos, afirmaram: "não conseguiria viver sem eles de jeito nenhum" e "arranjaria um meio de comprar outros rapidinho". Outros consumidores fizeram afirmações similares.

A constatação decorrente disso é, por fim, que o fato de os pobres urbanos terem obtido, nos últimos anos, acesso ao sistema de crédito pode ter alterado o seu comportamento de compra. Assim, o uso do carnê e do cartão de crédito disseminou-se entre os consumidores de baixa renda. A rede de lojas Casas Bahia, na visão de uma das entrevistadas, teria sido a primeira empresa a ter percebido a oportunidade de atender esse público, o que também contribuiu para esta importante e aparente irreversível mudança de hábito de consumo.

\section{CRÉDITO: USO DO CARNÊ E DO CARTÃO}

Desde o início do trabalho de campo, esta categoria apresentou-se como de grande relevância para a pesquisa. É escusado afirmar que diferentes formas de acesso ao crédito para a compra de produtos diversos, tais como o uso tanto do carnê de pagamentos quanto do cartão de crédito, estão bem disseminadas entre os pobres urbanos. Porém, o que se percebeu por meio da pesquisa foi que, apesar de grande parte deles afirmar que prefere pagar à vista, devido à percepção do juros abusivos cobrados em compras a prazo, afirmaram, também, espontaneamente, que optam por fazer compras utilizando formas de crédito, pois seria uma das poucas - se não a única - oportunidades de ter acesso ao consumo, principalmente de aparelhos novos e mais modernos. Assim, desde o início da pesquisa foi destinada grande atenção quanto aos aspectos envolvendo o uso de carnê e de cartão de crédito ao longo das observações e entrevistas.

Nas várias entrevistas conduzidas com as entrevistadas e nas conversas informais, a questão do acesso ao crédito foi bastante discutida. Cabe destacar que os consumidores pesquisados utilizavam as formas de crédito principalmente para a compra de roupas, móveis, material de construção, produtos eletrônicos, eletrodomésticos e, em caso de emergência, remédios. Quanto ao foco da pesquisa, o campo dos aparelhos eletrônicos, foi possível verificar que, exceto algumas situações nas quais os consumidores aproveitaram alguma promoção de vendas executadas pelas redes de varejo, todos os consumidores utilizavam alguma forma de crédito para obter seus produtos.

Alguns moradores do Cafezal perceberam que vem sendo cada vez maior a facilidade na obtenção de crédito. Muitos deles relataram que, antigamente, as lojas eram mais criteriosas no processo de concessão de crédito; era necessário ter carteira de trabalho assinada, possuir endereço fixo, apresentar uma série de documentos e não ter o nome "pendurado" nos órgãos de proteção ao crédito. Contudo, na época da pesquisa, conforme um dos entrevistados, "as lojas estavam fazendo 'vista grossa'", o que faz com que qualquer um "tenha um 'carro zero'". Constatou-se essa maior facilidade de acesso ao crédito quando o pesquisador solicitou a algumas das entrevistadas que mostrassem os tipos de cartões que utilizavam. Nas entrevistas, foi possível perceber que em todas as famílias vários integrantes têm cartões de crédito; às vezes, até mais de um.

Com relação à posse de cartão de crédito, uma constatação da proprietária da loja de móveis que mantém um comércio na região há mais de trinta anos está relacionada com a introdução desta modalidade de crédito entre os consumidores de baixa renda. Segundo ela, algumas "bandeiras", como Mastercard, têm destinado grandes esforços para atender às classes mais po- 
pulares. Ela relatou ao pesquisador que, do total de vendas de móveis da loja, quase $20 \%$ eram pagos com cartão, percentual muito maior do que há anos atrás.

\section{RE(ENCONTRO) COM A LITERATURA}

À luz da perspectiva da antropologia do consumo, os estudos de Thorstein Veblen, conduzidos no início do século XX, podem ser utilizados para iniciar a discussão referente ao retorno à literatura. Uma das principais argumentações do autor vai ao encontro dos resultados da pesquisa: existe uma modalidade de consumo que é ostentatória, realizada com a finalidade de demonstrar a condição social e que pode ser denominada de "consumo conspícuo", isto é, que objetiva uma diferenciação significativa e leva em consideração a hierarquia da sociedade. Nesse sentido, os aparelhos eletrônicos parecem funcionar como uma espécie de identificação da posição dos pobres urbanos não para efeitos de comparação com outras parcelas da população em geral, mas em relação aos próprios moradores do bairro, para diferenciá-los dos "muito pobres". Outra constatação decorrente da pesquisa que pode ser explicada pelos estudos de Veblen (1988) relaciona-se com a decisão dos consumidores de instalarem seus aparelhos eletrônicos sempre à vista de vizinhos e pessoas conhecidas. Ademais, os eletrônicos servem para ajudar a construção de relacionamentos e trocas sociais.

Algumas noções sobre os fatos da vida econômica na vida social, conforme fornecido pela interpretação de Sahlins (2003), também parecem ter tido ressonância. Para Sahlins, os objetos não têm qualidade intrínseca, e a utilidade dos bens é elaborada e permanentemente reelaborada na estrutura das trocas de uma comunidade cultural. Quanto à isso vale destacar que os aparelhos eletrônicos constituem-se como uma combinação até certo ponto indissociável entre praticidade e simbolismo.

É nesse mesmo sentido que foram desenvolvidas algumas análises com o suporte da perspectiva da cultura material proposta por Douglas e Isherwood (2006). A ideia importante desses autores é a de que é por meio dos significados públicos vinculados aos bens e de seus usos públicos que o consumo organiza a ordem social, trazendo à tona categorias sociais, entre outros. São essas classificações que determinam os significados das coisas e refletem a própria ordem social. Em outras palavras, os significados e rituais de consumo demarcam, portanto, as categorias que constituem a ordem social. Complementarmente, esses significados são utilizados nas práticas do dia a dia para construir e manter relações sociais.

Outra importante consideração de Douglas e Isherwood (2006) pertinente à esta pesquisa diz respeito ao conceito de consumo. Para os autores, o consumo funciona como um fluxo de informações que integra as pessoas em um mundo social inteligível. Dessa forma, os indivíduos usam o consumo para dizer alguma coisa sobre si mesmos, sobre sua família, sobre o lugar onde vivem etc.

As ideias de Campbell (2001) também foram importantes na medida em que ele considera que a sociedade de consumo atual caracteriza-se tanto pela importância dada à emoção e ao desejo quanto à dada ao papel do individualismo. Campbell (2001) defende a tese de que o consumo, ao invés de aprofundar a "crise de identidade" tão enfatizada pelos pós-modernistas, é uma atividade por meio da qual os indivíduos conseguem resolvê-la. Corroborando o que já foi dito por outros autores, o self do indivíduo é definido por seus gostos e por suas preferências pessoais, e o consumo teria o poder de funcionar como uma forma de conhecer e reconhecer quem ele é.

As análises de Bourdieu (1989, 2007a, 2007b) parecem ter alguma relação com os resultados da pesquisa, embora algumas ponderações sejam necessárias uma vez que o contexto em que o autor abordou em seus estudos é bastante diverso do investigado na pesquisa. A pri- 
meira questão está ligada ao conceito de habitus, que pode ser utilizado nesta pesquisa para tentar caracterizar sistemas de classificação, regras e expectativas que predispõem o indivíduo a fazer certas escolhas e ações. O conceito de habitus parece ser adequado, pois é possível afirmar que, ao contrário do que sustenta parte da literatura referente aos consumidores pobres, não é adequado considerá-los como uma classe homogênea, obediente e fiel a padrões fixos, uma vez que as camadas populares, como enfatiza Caldeira (1984), estão o tempo todo transitando por entre esses diversos planos, realidades, níveis e sistemas explicativos. Assim, cabe destacar que os resultados da pesquisa parecem corroborar com autores que advogam a favor da ideia de que não há um único grupo de características que possam ser utilizadas para classificar os consumidores pobres. Pelo contrário, somente a "multiplicação" de estudos etnográficos que levem em conta a inter-relação de todos os fatores constituintes das práticas do cotidiano desses indivíduos, incluindo questões supralocais e microlocais, poderá aprofundar o conhecimento acerca do consumidor de áreas pobres (ALVITO, 2001).

Além disso, para Bourdieu (2007), mais importante do que a posse em si, é a investigação do uso que os indivíduos são capazes de fazer desses bens. No relato da pesquisa, ficou explicitado que os pobres urbanos buscam distinção por meio dos seguintes aspectos: localização da casa, posse de casa própria e consumo de aparelhos eletrônicos, o que indica que é pela posse dos bens e, mais precisamente, pelo consumo que os pobres distinguem-se uns dos outros. Prova disso é que dentre os entrevistados, a todo momento, era possível perceber uma forma de busca de distinção entre os "pobres" dos "muito pobres". Constatou-se também que os aparelhos eram sempre instalados na sala, em locais que poderiam ser avistados pelos outros moradores ou pelos transeuntes da rua. A palavra-chave para esse processo social é o que Bourdieu (2007) chama de "distinção", termo que parece englobar o sentido de sistemas classificatórios por meio dos quais os indivíduos distinguem as coisas, bem como o uso dessas coisas e de seus significados para conseguir distinção nas relações sociais.

Alguns aspectos ressaltados por Miller (2002) podem ser considerados coincidentes com o que foi verificado no trabalho de campo. Miller (2002) enfatiza que comprar é um ato de amor, e, por isso, as compras tornam-se um dos meios fundamentais para a construção de relacionamentos tanto de amor e carinho quanto de preocupação, obrigação e responsabilidade na vida do cotidiano. Isso implica que os estudos envolvendo a cultura material não devem abordar a compra apenas como uma coisa em si, mas como um meio de descobrir algo sobre os relacionamentos sociais.

Desse modo, conforme implicitamente comentado anteriormente, o ato de comprar e consumir eletrônicos tem um significado importante para os pesquisados, visto que esses apareIhos representam uma forma de demonstrar amor, cuidado e atenção e de proporcionar maior conforto aos filhos e outros familiares. Ficou evidenciado que ter uma televisão nova, um DVD moderno e um aparelho de som mais potente representa uma "prova" de que as entrevistadas são boas mães e preocupam-se com o bem-estar de seus filhos. Ademais, seria uma forma de "minimizar" o fato de morarem em um bairro pobre e com estrutura urbana precária.

Esta pesquisa corrobora a tese de Miller (2002) de que, sobretudo os ricos, devido à sua facilidade de acesso aos diversos bens disponíveis na afluente sociedade de consumo, são materialistas. Muito pelo contrário, consumir é algo inerente ao ser humano, e o desejo por ter bens e usufruir deles não está somente relacionado à quantidade de recursos disponíveis nem à conta bancária. Nessa perspectiva, conforme Leitão, Lima e Machado (2006), o consumo é distintivo e demarcador de vidas e memórias, indiferentemente das classes sociais, e isso parece não ter relação direta com poder aquisitivo.

A noção de que existem apenas poucos objetos puramente utilitários, neutros, de modo 
algum carregados de significados sociais também deve ser aqui destacada. Quase todos são dissimuladores, têm um papel duplo, servem de "simulacro funcional, atrás do qual os objetos continuariam a desempenhar seu papel de discriminadores sociais" (BAUDRILLARD, 2005). Em outras palavras, Baudrillard (2005) parece afirmar que os indivíduos deixaram de consumir produtos; passaram a consumir signos. Isso significa dizer que o que se compra com o bem de consumo e por meio dele é a posição social que ele indica em relação a todos os outros signos-mercadorias do sistema.

A partir do confronto dos resultados da pesquisa com a literatura atinente ao campo da antropologia do consumo, torna-se possível delinear as considerações finais do trabalho.

\section{CONSIDERAÇÕES FINAIS}

Ao iniciar a seção de considerações finais, não é escusado colocar algumas questões que, mais do que pertinentes, parecem ser essenciais para esse capítulo. Em primeiro lugar, ao analisar os resultados do trabalho, parece ser útil enfatizar que não somente é possível, mas essencial avançar por novos enquadramentos conceituais sobre o consumo e o consumidor que desafiem a forma costumeira de compreendê-los, somente por meio de uma dimensão residual, individual ou utilitária advinda de uma visão reduzida. Uma das conclusões desta pesquisa é a de que deve-se compreender o consumo como uma espécie de facilitador, propiciador e construtor de relações sociais. Dessa forma, as experiências de consumo no plano simbólico implicam atrelar aos significados dessas experiências às dinâmicas de sociabilidade.

Em segundo lugar, é importante salientar que os resultados obtidos referem-se especificamente ao fenômeno pesquisado na área substantiva: as experiências de consumo de eletrônicos por consumidores de baixa renda da vila Cafezal, uma das vilas que compõem o Aglomerado da Serra, um dos bairros pobres da cidade de Belo Horizonte. Generalizações para outras localizações de outras partes de Belo Horizonte ou do Brasil devem ser feitas com cautela e conduzidas criteriosamente.

A pesquisa conduzida possui características das abordagens interpretativas e, como tal, recebe influência dos preconceitos e pressupostos do pesquisador nas descobertas e nas análises dos dados, o que implica alta dose de subjetividade da pesquisa. Nesse caso, em que a pesquisa foi conduzida por apenas um pesquisador, pode-se dizer que o risco de as interpretações possuírem vieses e reflexos de ideologias e interesses pessoais é considerável. Porém, buscou-se a minimização dessas limitações, seja por meio da conjugação de diferentes tipos de coleta de dados por meio de entrevistas pessoais e observação. Ademais, lançou-se mão das orientações de diversos autores, conforme discutido no capítulo acercada do percurso metodológico, para garantir a confiabilidade dos dados de campo e das interpretações conduzidas.

Cumpre destacar, por fim, que o trabalho descortina uma série de possibilidades de pesquisas no tocante à cultura material. $O$ rol de possibilidades ultrapassaria o escopo desta seção do artigo, principalmente quando se tem como foco o entendimento da complexidade dos significados culturais presentes nas diversas situações de consumo, a fim de mapear a heterogeneidade de significados construídos pelos diversos grupos integrantes de dada sociedade. Quanto à temática "consumo entre os pobres urbanos", diversas investigações poderiam caminhar no sentido de buscar entendimento no que tange às diferenças verificadas entre os próprios consumidores, opondo-se ao senso geral de que eles apresentam as mesmas características, devendo ser tratados de forma homogênea e unificada. Ganham vulto, por conseguinte, estudos que busquem interpretar os significados articulados por eles nas diversas experiências de consumo tais como nos ambientes de varejo, nas estratégias de relacionamento das empresas, nas comunicações de marketing, nas interações proporcionadas pelos serviços, nas campanhas de marketing social, entre outros. 


\section{REFERÊNCIAS}

ALVITO, Marcos. As Cores de Acari: Uma favela carioca. Rio de Janeiro: Editora FGV, 2001.

ANDION, Carolina; SERVA, Maurício. A Etnografia e os Estudos Organizacionais. IN: GODOI, Christiane K; BANDEIRA-DE-MELLO, Rodrigo; SILVA, Anielson B. (org.) Pesquisa Qualitativa em Estudos Organizacionais: paradigmas, estratégias e métodos. São Paulo: Saraiva, 2006.

BARBOSA, Lívia. Apresentação. IN: BARBOSA, Lívia; CAMPBELL, Colin (org). Cultura, Consumo e Identidade. Rio de Janeiro: Editora FGV, 2006.

BARBOSA, Lívia; CAMPBELL, Colin. O Estudo do Consumo nas Ciências Sociais Contemporâneas. IN: BARBOSA, Lívia; CAMPBELL, Colin (org). Cultura, Consumo e Identidade. Rio de Janeiro: Editora FGV, 2006.

BARDIN, L. Análise de Conteúdo. Lisboa: Edições 70, 1977.

BARROS, Carla F. A "Invisibilidade" do Mercado de Baixa Renda nas Pesquisas de Marketing: as Camadas Populares Consomem ou Sobrevivem? In: Encontro de Marketing - EMA, 2‥ Anais... Rio de Janeiro: ANPAD, 2006.

BAUDRILLARD, Jean. A Sociedade de Consumo. Lisboa: Edições 70, 2005.

BOURDIEU, Pierre. O Poder Simbólico. Rio de Janeiro: Bertrand Brasil, 1989.

BOURDIEU, Pierre. A Economia das Trocas Simbólicas. São Paulo: Perspectiva, 2007a.

BOURDIEU, Pierre. A Distinção: crítica social do julgamento. São Paulo: Edusp; Porto Alegre: Zouk, 2007b.

CALDEIRA, Teresa P. do R. A Política dos Outros: O cotidiano dos moradores da periferia e o que eles pensam do poder e dos poderosos. São Paulo: Brasiliense, 1984.
CAMPBELL, Colin. The New Wave of Research in the Humanities and Social Science. Journal of Social Behavior and Personality, v. 6, n.6, p. 57-74, 1991.

CAMPBELL, Colin. A Ética Romântica e o Espírito do Consumismo Moderno. Rio de Janeiro: Rocco, 2001.

DOUGLAS, Mary; ISHERWOOD, Baron. O Mundo dos Bens: Para uma antropologia do consumo. Rio de Janeiro: Editora UFRJ, 2006.

DURHAM, Eunice R. A Pesquisa Antropológica com Populações Urbanas: Problemas e perspectivas. In: CARDOSO, Ruth C. L. A Aventura Antropológica: Teoria e pesquisa. Rio de Janeiro: Paz e Terra, 1986.

FLACH, L.A autogestão ensinando e encenando: um estudo etnográfico em uma organização cultural de Porto Alegre. Revista de Administração da UFSM, v. 4, n. 3, art. 4, p. 378-389, 2011.

LEITÃO, Débora K.; LIMA, Diana N. O.; MACHADO, Rosana P. Introdução. IN: LEITÃO, Débora K.; LIMA, Diana N. O.; MACHADO, Rosana P. Antropologia \& Consumo: Diálogos entre Brasil e Argentina. Porto Alegre: AGE, 2006.

MCCRACKEN, Grant. Cultura e Consumo: novas abordagens ao caráter simbólico dos bens e das atividades de consumo. Rio de Janeiro: Mauad, 2003.

MILLER, Daniel. Teoria das Compras: o que orienta as escolhas dos consumidores. São Paulo: Nobel, 2002.

PINTO, M. R.; LARA, J. E. O que se publica sobre comportamento do consumidor no Brasil, afinal?.Revista de Administração da UFSM, v. 1, n. 3, art. 2, p. 85-100, 2008.

PREFEITURA MUNICIPAL DE BELO HORIZONTE. Disponível em www.pbh.gov.br. Acesso em jan. 2008. 
ROCHA, Angela da; ROCHA, Everardo. Paradigma Interpretativo nos Estudos de Consumo: Retrospectiva, Reflexões e uma Agenda de Pesquisas para o Brasil. Revista de Administração de Empresas. V. 47, n. 1, p. 7180, jan/mar 2007.

SACCOL, A. Z.Um retorno ao básico: compreendendo os paradigmas de pesquisa e sua aplicação na pesquisa em Administração. Revista de Administração da UFSM, v. 2, n. 2, art. 6, p. 250-269, 2009.

SAHLINS, Marshall D. Cultura e Razão Prática. Rio de Janeiro: Jorge Zahar, 2003.

STRAUSS, Anselm; CORBIN, Juliet. Pesquisa Qualitativa: Técnicas e procedimentos para o desenvolvimento da teoria fundamentada. 2a edição. Porto Alegre: Artmed, 2008.

VEBLEN, Thorstein. A Teoria da Classe Ociosa: um estudo econômico das instituições. São Paulo: Nova Cultura, 1988. 